\title{
Comparison 2 methods of resistance training (conventional and bodypump) on the agility and vertical jump in male basketball players $16-18$ years
}

\author{
Hamid Reza SALIMI, Amir Hosein BARATI, Nahid ADIBPOUR
}

Shahid Rajaee Teacher Training Univercity, Faculty of Physical Education and Sport Scienc, Tehra, Iran.

Address Correspondence to HR salimi, e-mail: salimihamid55@yahoo.com

\begin{abstract}
The aim of this study was to compare an bodypump and resistance training on agility and vertical jump on male basketball players 16-18years. Therefore 36 teenage basketball players voluntarily chosen and randomly divided into three groups including: bodypump group ( $\mathrm{n}=12$,age $17 \pm 0.5$ year, height $179 \pm 0.05 \mathrm{~cm}$ and a weight $69.26 \pm 12.22 \mathrm{~kg}$ ) and resistance group $(\mathrm{n}=12$, age rangen $17 \pm 0.6$ years, range height $178 \pm 0.09 \mathrm{~cm}$ and weight $68.55 \pm 14.25 \mathrm{~kg})$ and control group $(\mathrm{n}=12$, age $17 \pm 0.5$ years, height $179 \pm 0.06 \mathrm{~cm}$, and the weight $70.06 \pm 8 \mathrm{~kg}$ ), respectively. Experimental groups were carried out of 8-weeks of typical training. Before and after 8 weeks, the subjects were tested. Vertical jump was measured by Sargent and agility was measured by T test. For analysis data one way ANCOVA and Bonferroni test were used. Measurements between groups indicated that the difference was significant, and Bonferroni test showed that between experimental and control groups difference was significant, but the difference between the experimental groups was not significant. It can be concluded, both methods had the same effect on vertical jump and agility. Therefore, in order for basketball players within 16-18 age group to improve them, they can utilize one of the two methods on their own choice. Coaches should be based on intensity, duration, discipline, control and supervise the performance, since bodypump method does not require expensive and complex devices, and can be performed with a number of dumbbell and barbell and control and supervise the performance due to the implementation of harmonic and simultaneous movements easier and the effectiveness of the conventional method was similar, for this reason can be suggested used in a large number of the club's athletes and the cost and time is important to them to be used.
\end{abstract}

Keywords: Agility, bodypump training, conventional resistance training, vertical jump.

\section{INTRODUCTION}

There has been a significant increasing in the sport science fields during the recent years and fitness, as an important part of this science, has acquired a large variety, evolution and development. Safrit had classified the fitness into two groups: health-related fitness and performancerelated fitness. The components of health-related fitness includes body composition, cardiovascular fitness and flexibility, strength and endurance; while the performance-related fitness components includes power, speed, muscles strength and endurance, agility, balance, coordination and reaction time (18). In the sport field majorities, there are some skills and movements that heavily rely on physical fitness, strength and power (20). For example, power represents itself in movements such as jumping, rebounding in basketball, and quick changes of direction in handball, soccer and quick spike in volleyball. Reaching the highest vertical level in a jump is an advantage for basketball players, because they can throw the ball into the basket at higher level than the opponent players or receive the rebounding ball from the basket at higher level than other players (11).

Basketball is a sport field with high level of physical activity containing many quick and sudden movements, and has a periodic nature which requires high level of aerobic and anaerobic fitness. Paul et al, in a study of physical and physiological needs in basketball practice and competition to the conclusion that physical and physiological responses similar training requirements and to defend and offence and 5 on 5 games against physical and physiological needs more considerably (14). Ostojic et al., physical and physiological characteristics of elite basketball players studied and they found a strong relationship between body 
composition, aerobic fitness, fitness,anaerobic power, and players position in the elites basketball (12). According to Huffman et al, factors such as agility, power, balance and speed are very important for this sport field to such an extent that these factors are regarded as superiority of one team over its opponent. Speed and agility as both undeniable factors in predicting college male basketball players of the game have been grouped NCAA level. Agility is an important factor in the efficiency of basketball (5). In basketball agility redirects in defense and offence which acceleration will be apply. Regular and appropriate exercises related to basketball field is necessary to improves these factors.

Sport exercises generally improve human performance, but what should we do if we like to maximize this skill in a steady way? In order to show the maximum level of performance, athletes and coaches have utilized many approaches so far. Nowadays, resistance training is used as a part of training routine in many sport fields $(9,16)$. Positive effects of resistance training depend on variation of different factors like intensity, volume and exercise type. During the recent years, exercise volume has been considered as one of the most important factors for resistance training. Especially, single-session exercises with higher level of intensity to save more time have attracted more attention, in contrast to a multi-session exercise (19); also, group exercises are preferred over individual exercises due to higher psychological effect of group exercise; aerobic exercises is a case in point in this regard. Since many years ago, various methods have been introduced for resistance exercises such as pyramid, single-set, super set methods and their advantages and disadvantages have been clarified with time by various research studies. This trend is still continuing and many modern methods have been created with new advancement in sport science. One of the new methods with have gained high popularity around the worlds is "body pump" method (15). This method is performed using barbell and dumbbell and playing music. Vaughan et al. (21) and Pfitzinger \& Lythe (15) have introduced this exercise as a low intensity exercise, high repetition resistance workout which is performed in groups. I did it because intensity is a different rate of combination which the weights are increased and it also increases blood flows from heart to muscles and it will speeds up the fat-burning process $(15,21)$.

Working with youngsters and adolescents has always been both interesting and accompanied with many problems like injuries caused by sport activity, overtraining, exhaustion, Supervision and control on Intensity and duration. Resistance training in this age range has always been full of risks and challenges. Concerning the novelty of this topic and lack of sufficient studies and also the basic physical needs for basketball players in this age group, the authors aimed to make a comparison between two resistance training routines (conventional [traditional] and body pump) on vertical jump and agility among male basketball players within age range of 16-18 years old.

\section{METHODS}

In this experiment 36 teenage basketball player voluntarily chosen and randomly has divided into three groups. Including: body pump group ( $n=12$, age range $17 \pm 0.5$ year, height $179 \pm 0.05 \mathrm{~cm}$ and a weight range $69.26 \pm 12.22 \mathrm{~kg}$ ) , The conventional resistance group $(n=12$, age rangen $17 \pm$ 0.6 years, range height $178 \pm 0.09 \mathrm{~cm}$ and weight $68.55 \pm 14.25 \mathrm{~kg})$ and the control group $(\mathrm{n}=12$, age range $17 \pm 0.5$ years,range, height $179 \pm 0.06 \mathrm{~cm}$, and the weight range $70.06 \pm 8 \mathrm{~kg}$ ),respectively. The field study was a pretest-posttest design. The experimental groups after 8-weeks of typical training and the control group just have trained basketball.

The protocol of conventional resistance training includes: 3 sets of 50,60. 80 percent of 1RM of each exercises, for two times per week and to overload conduction of principle 1RM test was measured in 2end, 4end and 6end weekends respectively. All the required conditions assumed for conventional resistance training group were also assumed for the body pump group. In this method simultaneously, of dumbbell and barbell bodybuilding machine was used. The movements of this training method include: Triceps Variations, Bicep Curl, Cleaning and Pressure/Power Pressure, Lunge, Deadlift Variation, Chest Pressure, Shoulder Variations, Push up, pull up Variations, Squat Variations, leg pressure, knee extension/flexion, core stability Variations.

Body pump training, which has been introduced as a type of low-intensity, highrepetition resistance trainings in the literature, is composed of 9 tracks, in which each muscle group had a separate workout for 5-7 minutes like as figure 1 . Total duration of each session lasted between 5060 minutes. Each tone groups contained 70- 100 repetition target muscles. Totaling up to 800 repetitions in a single workout.This type of training could be performed by dumbbell and barbell. This 
training movements methods are includes: Triceps Variations, Bicep Curls, Cleaning and Pressure/Power Press, Lunge, Deadlift Variations, Chest Pressure, Shoulder Variations, Push up, pull up Variations, Squat Variations, leg pressure, knee extension/flexion, stability core Variations.

In body pump resistance training method, the weight could not be increase due to be different rate exercises. Experimental groups had two sessions of dedicated training per week, and one common session of basketball training with control group. Two experimental groups have completed 8 weeks of typical resistance training regime and have engaged in regular basketball training class like the control group.

In this study short time power (vertical jump) or sergeant test was used for power measuring output. All subjects completed the 3 vertical jumps, and their best performance was recorded as their marks.

Also, in order to evaluate agility, $\mathrm{T}$ test was used. According to figure 2, the subject has heard the sign "Go with all of speed from the left side to the central barrier". When the subject was a central barrier to barrier slide (boxing) of the left moves, then back again to the center, it passes and goes to the right. Centre back again and this time the back pedal to the initial position. His record is recorded in seconds. This test is repeated three times for each Subject record and it is the best record for him.

Values were expressed as means \pm SD. The normal distribution of the data was check using the Kolmogorov-Smirnov test. After confirming normal distribution, one-way ANCOVA was used for comparing differences and Bonferroni posthoc test was used for post-hoc comparisons. For all tests, $\mathrm{P}<0.05$ was considered as significant, All statistical tests performed using SPSS software (version 18) and Excel software (office word 2007 version) was used to draw the figures.

\section{RESULTS}

Descriptive characteristics of the subjects are shown in table 1. It is clear from Results of this study (table 2 and 3) that both experimental groups performance(vertical jump and agility) was incresed after intervention of 8 week resistance training comparing to control group.

Table 1. Mean and standard deviation (SD) of age, height, veight and bmi across groups.

\begin{tabular}{cccc}
\hline Group variable & Bodypump & Resistance & Control \\
\hline & & & \\
Age & $17 \pm 0.5$ & $17 \pm 0.6$ & $17 \pm 0.5$ \\
Height $(\mathrm{cm})$ & $179 \pm 0.05$ & $178 \pm 0.09$ & $179 \pm 0.06$ \\
Weight $(\mathrm{kg})$ & $69.26 \pm 12.22$ & $68.55 \pm 14.25$ & $70.06 \pm 8$ \\
BMI $\left(\mathrm{kg} . \mathrm{m}^{2}\right)$ & $21.5 \pm 3.6$ & $21.6 \pm 3.3$ & $21.8 \pm 1.12$
\end{tabular}

Table 2. Results of vertical jump and agility univariate across groups.

\begin{tabular}{|c|c|c|c|c|c|c|c|c|c|c|c|}
\hline \multicolumn{6}{|c|}{ Vertical jump } & \multicolumn{6}{|c|}{ Agility } \\
\hline & $\begin{array}{l}\text { Sum of } \\
\text { Squares }\end{array}$ & $\begin{array}{l}\text { Mean } \\
\text { Square }\end{array}$ & $\mathrm{F}$ & $\mathrm{P}$ & $\mathrm{y}^{2}$ & $\begin{array}{l}\text { Sum of } \\
\text { Squares }\end{array}$ & $\begin{array}{c}\text { Mean } \\
\text { Squares }\end{array}$ & $\mathrm{F}$ & $\mathrm{P}$ & $\mathrm{n}^{2}$ & $\mathrm{df}$ \\
\hline group & 68.16 & 34.08 & *64.43 & 0.001 & 0.81 & 0.26 & 0.13 & 0.22 & 0.80 & 0.015 & 2 \\
\hline Error & 15.33 & 0.52 & & & & 16.83 & 0.58 & & & & 29 \\
\hline
\end{tabular}

*Significant differences $\mathrm{p} \leq 0.05$.

Table 3. The findings from the Bonferroni test in comparison to the average vertical jump and agility into three groups.

\begin{tabular}{|c|c|c|c|c|c|}
\hline Variable & & Group & Mean difference & Estandaed Error & $\mathrm{p}$ \\
\hline \multirow[t]{4}{*}{ Vertical jump } & Bodypump & Resistance & 0.186 & 0.305 & 1 \\
\hline & Resistance & Bodypump & 0.186 & 0.305 & 1 \\
\hline & & Control & 3.02 & 0.323 & ${ }^{*} 0.001$ \\
\hline & Control & Bodypump & 3.21 & 0.309 & ${ }^{*} 0.001$ \\
\hline
\end{tabular}

* Significant differences $\mathrm{p} \leq 0.05$. 


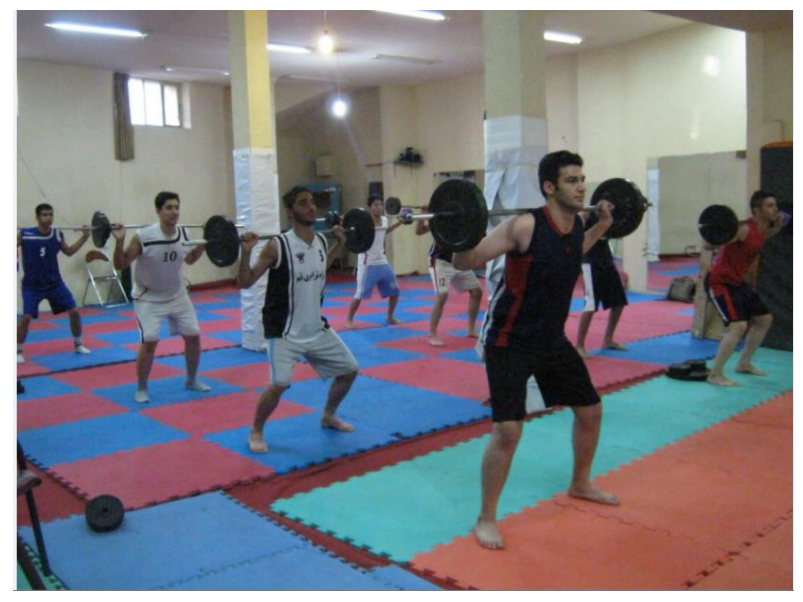

Figure 1. Bodypump exercises

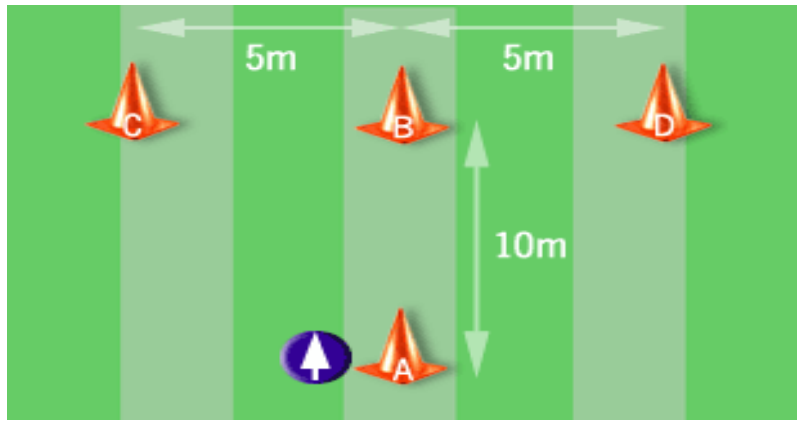

Figure 2. $\mathrm{T}$ test

\section{DISCUSSION}

In this study, it was observed that both resistance training (conventional and body pump) had significant effect on vertical jumps, which means that body pump training and resistance training both improved record related to the vertical jumps, but had no significant effect on agility. Furthermore, in vertical jumps, examination the intergroup changes revealed that there was a significant difference between experimental group and the control group; however, no significant difference was observed between the two training groups. There was no difference between groups in agility record.

Agility is defined as the ability to change speed and direction accurately and without losing balance. The index factors such as strength, speed, velocity, reaction time, balance, strength and flexibility depends (8). Basketball is a intense sport which is why every moment need to sudden change to take places, That means the basketball player have to prepare himself with a high agility. So where agility is an important indicator.

Several studies have been done on various ways on the developments of power and strength. resistance training increases protein synthesis and hypertrophy of muscle contractions, especially twitch fibers fast thus an athlete's agility improves $(4,10)$ but that didn't occur in the present study.

Perhaps reason of this discrepancy is; because basketball is a intensity training, and basketball players may have reached a level flat. Results of previous studies shows that exercise training can only be effective such programs and agility training methods on the implementation of a combination of contractions and shortened muscle elongation, with a shorter time interval than the time need used. The conventional resistance training does not have this feature, but the body Pump with the combination of speed it had been carrying weight was used in the most eccentric and concentric type was contracted. But perhaps it's more time the contractions can affects the agility, in other words, the contraction speed time in two ways improve agility training couldn't provides the necessary factors.

Vertical jump in basketball is an example of a power activity. Under best condition during a sport session, power defined as product of strength and speed (8). In basketball, power has been represent itself in jump shooting, rebounding and sudden changes of direction. For many years, athletes and 
coaches in order to improve athletic performance, which trying to increase the power, its combination of strength and speed, strength will be increased power, indirectly. Increased cross bridges and powerful concentric phase, created with the increase in muscles cross-section. By strengthening tendons, and increase muscles collagen content, increased tensile strength of connective tissue and therefore increased elasticity energy resources and leading to improve the short-stretch cycle performance (14). Since many years ago, increasing strength has been proven a direct result of increase in muscles volume (hypertrophy). Although this is a logical statement, there some evidence that neural control in an increased muscle to produce more power out. Nervous system has a considerable role in increasing strength caused by resist training. By a convincing discussion, Enoka states that increased although strength can be obtained without change in muscle structure; it is impossible neural adjustment $(9,22)$. Thus, strength not merely characteristics of a muscle, but it's considered from properties of a motor system. The motor system is a significant factor in increasing the strength.

This point can explain a part of increased strength in absence of hypertrophy as well as in superhuman strengths. Increased strength can be the result of changes in relation with motor neurons have located at vertebral column which causes further coordination of motor units, facilitation and increase in muscles' force-producing capability. Motor units generally are called upon at different times. Motor units are controlled by a group of neurons. These nerve cells are able to pass stimulating and inhibiting motivation. There are various evidences that tell supporting the simultaneous increase in motor units via resistance training, but still contradictory results about whether coordination of motor units activation can producing a high level of muscle contraction $(3,22)$. This is obvious that synchronization improves level of force production and capacity of application of sustainable force.

Another possibility is that without including simultaneous action of motor units, larger numbers of units are employed for specific tasks. Such an improvement in recruitment models can be caused by increased nervous flow to alpha motor neuron during maximum contraction. The increase in the motor units are nervous can be a maximum discharge. This is also possible that inhibiting impulses decrease and allow for further activation of motor units or continue their activity with higher frequency $(8,22)$. Researches have shown that standard trainings with weights can improve power (8). It has also been proven that exercises an effective factor for increasing power are dynamic (8). Several studies have reported that performing squat exercise with heavy lifts results had improved performance in vertical jump $(3,6,22)$. Also, variety of speed at which the weights are lifted has also demonstrated different results.

Researchers have a unanimous agreement that high and intermediate repetitions are required in order to gain hypertrophy and muscular endurance; while low repetitions with high loads are needed for muscular strength (17). Investigating effect of three resistance training methods (slow, intermediate and fast) on muscle's EMG responses among non-athlete males. Arazi et al. (1) investigated effect of three resistance training methods (slow, intermediate and fast) on muscle's EMG response among non-athlete males. They showed that there was no significant difference between these three methods (1). Moreover, Hoseini et al. studied the acute effects of two resistance trainings with intermediate intensity, the same volume as well as slow and fast speeds on some of the anabolic and catabolic hormones and concluded that slow and fast resistance training after the training session can significantly increase level of the growth hormone immediately (7). However, there was no significant difference between that two training methods. Slow resistance training had greater impact on secretion than testosterone growth hormone, compared to fast resistance training. Slow and fast resistance trainings had no effect on cortisol, insulin and glucose (2).

Body pump training method, which has been introduced as a high repetition, low volume resistance training and its capability to improve strength and power, agility and endurance has been shown by literature, uses both slow and fast resistance training $(15,21)$. Vaughan et al. investigated the effects of body pump method on strength, balance and walking rate among healthy elderly people (21). The results showed that this method increases strength and improves balance and walking rate among the subjects. Results of the present study are in agreement with results of Paul et al. (2003) and on effect of resistance training on power. However, due to novelty of body pump method, there are only a limited number of researches in this area available to the author.

According to this study results, there was no significant difference regarding effect of both 
training methods, i.e. both methods had the same effect on vertical jump. Therefore, in order for basketball players within 16-18 age group to improve their vertical jump, they can choose between one of the methods. Resistance training is for adolescents and young athletes to certain conditions. For example, coaches should be based on intensity, duration, discipline and control and supervise the performance, since body pump method does not require expensive and complex devices, and can be performed with a number of dumbbell, barbell, control and supervise the performance due to the implementation of coordinated and simultaneous movements more easier and the the conventional effectiveness method was similar, because of this, they can be suggested used in a large number of the club's athletes and the cost and time is important to them to be used.

\section{ACKNOWLEDGEMENTS}

The authors would like to thank all athletes, and coaches for their kind participation in the study.

\section{REFERENCES}

1. Arazi H, Mirzaei B, Heidari N. Neuromuscular and metabolic responses to three different resistance exercise methods. Asian journal of sport medicine.2014; 5(1): 30-38.

2. Goto K, Ishii N, kizuka T, Kraemer RR, Honda $\mathrm{Y}$ and Takamatsu $\mathrm{K}$.hormonal and metabolic responses to slow movement resistanse exercise with different durations of concentric and eccentric actions.2009; Eur J Appl Physiol; 106: $731-739$

3. Gourgoulis V, Aggeloussis N, Kasimatis P, Mavromatis G, Garas A . "Effect of a submaximal half-squats warm-up program on vertical jumping ability". Journal of Strength andConditioning Research.2003;17(2):342-344.

4. Häkkinen $\mathrm{K}$, Pakarinen A, Kraemer WJ, Häkkinen A, Valkeinen H, Alen M. Selective muscle hypertrophy, changes in EMG and force, and serumhormones during strength training in older women.Journal of AppliedPhysiology. 2001;91(2): pp:569-80.

5. Hoffman, J. R. Physiology of Basketball, in Handbook of Sports Medicine and Science: Basketball (ed D. B. McKeag), Blackwell Science Ltd, Oxford, UK..2003;1-64.

6. Hoffman J R, Ratamess N A, Faigenbaum A D, Mangine G $\mathrm{T}$, Kang J ."Effects of maximal squat exercise testing on vertical jump performance in American college football players". Journal of Sports Science and Medicine.2007; 6:149-150.
7. Hoseini Kakhak S A, Jaberi Shahraki M, Hamedinia M R . Acute effects of moderate intensity resistance training program, the size and speed of slow and fast on some anabolic and catabolic hormones. Journal of biological sciences. 2014;2, 205-2018.

8. Sharkey J, Gaskill B. Sport physiology for coaches.2006; Human Kinetics, Health \& Fitness. USA.

9. Kraemer WJ, Ratamess N. Fundamentals of Resistance Training: Progression and Exercise Prescription. Official journal of American College of Sports Medicine.2004; 674688.

10. McArdle WD, Katch FI, Katch VL. Essentials of exercise physiology. Lippincott Williams \& Wilkins; 2006.

11. McLeod TC, Armstrong T, Miller M, Sauers JL. Agility improvements in female high schoolbasketball players after a 6-week neuromuscular-training program. J Sport Rehabil, 2009; 18(4): 465-81.

12. Ostojic SM,Mazic S; Dikic N.physical and physiological characteristics of elite players.Journal pf strength and conditioning research.2006;20(4)

13. Paul Collins.power training. Sport Publishers' Association (WSPA).2008;13-20.

14. Paul G. Montgomery, David B. Pyne, and Clare L. Minahan.The Physical and Physiological Demands of Basketball Training and Competition. International Journal of Sports Physiology and Performance, 2010, 5, 75-86.

15. Pfitzinger P, Lythe. Aerobic Consumption and Energy Expenditure During Body Pump. Fitness \& Performance Journal.2003; 2(2):113-120.

16. Rippetoe M \& Kilgore L . Practical Programming for Strength Training, 3 edition , Aasgaard Company.2008;59205

17. Rixon P K, Lamont H S, Bemben M G. "Influence of type of muscle contraction, gender, and liftingexperience on Postactivation potentiation performance". Journal of Strength and ConditioningResearch.2007;21(2), 500-505.

18. Safrit, M.J,Wood,T.M . Introduction to Measurement in and Education Exercise. 3 rd ed.st.Louis,Mosby-Year Book.1995.

19. Schlumberger, A.S.J.; and Schmidtbleicher, D . "Single vs multiple-set strength training in Women", Journal of Strength and Conditioning Research.2201; 15(3), 284-289.

20. Shumway-Cook A, Woollacott MH . Motor control: translating research into clinical practice. 1th Ed.United Stated: Lippincott Williams and Wilkins.2006.

21. Vaughan P. Nicholson Mark R. McKean Brendan J. Burkett - Low-load high-repetition resistance training improves strength and gait speed in middle-aged and older adults. Journal of Science and Medicine in Sport.2014.

22. Willmore JH, Costill LD, Kenney L . physiology of sport and exercise. Human Kinetics, Health \& Fitness, 2008. 